\title{
LAS CAUTELAS INNOMINADAS EN EL PROCESO LABORAL COLOMBIANO: INSTRUMENTO DE LA TUTELA JURISDICCIONAL EFECTIVA*
}

\author{
INNOMINATE CAUTIONS IN THE COLOMBIAN \\ LABOR PROCESS: INSTRUMENT OF EFFECTIVE \\ JURISDICTIONAL CONSERVATORSHIP
}

\author{
Edith Nathali León Moreno** y Jenny Marcela Mayorga Camacho***
}

Recibido: 11 de marzo de 2017 - Aprobado: 15 de diciembre de 2017.

* Artículo Inédito.

El presente escrito hace parte del trabajo de grado presentado para optar el título de Abogadas, en la Universidad Libre Seccional Socorro, el cual obtuvo la distinción de Laureado.

Para citar el artículo: LEÓN MORENO, Edith Nathali y MAYORGA CAMACHO, Jenny Marcela. Las cautelas innominadas en el proceso laboral colombiano: Instrumento de la tutela jurisdiccional efectiva. Revista del Instituto Colombiano de Derecho Procesal. No. 46 Julio - Diciembre. 2017, pp. 205-228.

* Miembro activo del grupo de Investigaciones Jurídicas y Socio Jurídicas IUS-PRAXIS de la Universidad Libre, Seccional Socorro. Abogada. Con estudios en Docencia Universitaria, estrategias pedagógicas para el Desarrollo del Pensamiento, Metodología de la Investigación en la Escuela de Formación de la Universidad Libre; estudios en Mecanismos Alternativos de Solución de Conflictos, en la Cámara de Comercio de Bucaramanga; Políticas Públicas para las Víctimas y Construcción de paz, del Instituto Interamericana de Derechos Humanos; y estudios en el Sistema Interamericano de Derechos Humanos, en el Instituto Colombiano de Derechos Humanos. Contacto: edithnathalileonm@gmail.com

*** Abogada. Con estudios en Mecanismos Alternativos de Solución de Conflictos, en la Cámara de Comercio de Bucaramanga; y estudios en el Sistema Interamericano de Derechos Humanos, en el Instituto Colombiano de Derechos Humanos. Contacto: marce.771@hotmail.com 


\title{
Resumen
}

Las medidas cautelares innominadas fueron incorporadas al ordenamiento, con la finalidad de salvaguardar el derecho sustancial encriptado en las pretensiones. Previa petición de parte, se le traslada al juez la responsabilidad de estimar la medida cautelar más conveniente y proporcional para garantizar una tutela jurisdiccional efectiva del mismo. El objetivo de la investigación, fue determinar los argumentos que presentan a las cautelas innominadas como un instrumento procesal laboral que garantiza la tutela jurisdiccional efectiva. Empleando un diseño metodológico cualitativo, transeccional descriptivo, exploratorio y propositivo; y el método teórico deductivo

y de análisis, se logró precisar que el ordenamiento laboral colombiano carece de medidas cautelares idóneas para garantizar la primacía del derecho sustancial y el acceso a la administración de justicia, por ello, se propone la implementación de las cautelas innominadas, inicialmente mediante remisión analógica; pero, en procura de no atentar contra el principio de gratuidad el desarrollo legal es necesario.

Palabras clave: Acceso a la justicia, derecho procesal laboral, derecho sustancial, medidas cautelares innominadas, tutela jurisdiccional efectiva.

\begin{abstract}
The unnamed precautionary measures were incorporated into the legal system, with the purpose of safeguarding the substantive right encrypted in the pretensions. Previous request of a part, the responsibility is transferred to the judge for estimating the most convenient and proportionate precautionary measure to ensure effective judicial protection of the same. The objective of the investigation was to determine the arguments presented to the unnamed cautions as a labor procedural instrument that guarantees effective judicial protection. Using a qualitative, descriptive, exploratory, and propositional methodological design; and the theoretical method deduction and analysis, it was possible to point out that the Colombian labor system lacks adequate precautionary measures to guarantee substantive law primacy and justice administration access. Therefore, it is proposed to implement the unnamed precautions, initially through analogue referral; however, in order not to violate the principle of gratuitousness, its legal development is necessary.
\end{abstract}

Key words: Access to justice, procedural labor law, substantive law, precautionary measures unnamed, effective jurisdictional protection. 


\section{Planteamientos introductorios}

La incansable búsqueda de un proceso y las vías procedimentales adecuadas para suplir los requerimientos del régimen laboral, tienen el objetivo de proporcionar una justicia real a las relaciones que surgen de dos fuerzas como lo son el capital y el talento humano. El conjunto de actos armónicos y/o coordinados, se encarrilan hacia un pronunciamiento que tutele los derechos fundamentales de los sujetos intervinientes en una relación laboral, mediante la adecuación de un proceso sencillo, ágil, eficiente y primordialmente garantista del derecho sustantivo.

Bajo este sendero, la función cautelar del juez laboral encuentra su máximo esplendor al ofrecer una protección idónea al derecho objetivo del demandante, garantizando de esta manera la efectividad de la justicia material, preconizada en el artículo 228 de la Constitución Política.

Empero, el principio de taxatibilidad enfocado a las medidas cautelares en el orbe laboral, coarta la posibilidad de ofrecer soluciones ágiles, adecuadas e idóneas para cautelar los horizontes del derecho objetivo. Por su parte, el juicio de razonabilidad efectuado por el administrador de justicia, en el momento de decretar una medida cautelar que no se encuentra taxativamente señalada en el andamiaje procesal (innominada), proporciona instrumentos lógicos y apropiados para cumplir con el verdadero fin de un Estado Social y Democrático de Derecho, acepción empleada por el filósofo Jürgen Habermas, en donde debe primar el principio rector de la dignidad humana de quien confía en el juez como figura que encarna el régimen de justica imperante.

Respecto al principio fundante del aseguramiento de la sentencia, se consagra, bajo la Ley 712 de 2001 (Art. 37-A), la posibilidad de decretar medidas cautelares en el proceso ordinario laboral, posterior a que el juzgador dilucide el fumus bonis iuris y el periculum in mora. El instrumento cautelar quedó contemplado en el Código Procesal del Trabajo y de la Seguridad Social (Decreto-Ley 2158 de 1948, en adelante CPTSS), en su artículo $85 \mathrm{~A}$, consistente en el pago de una caución por parte del demandado por un valor entre el 30\% y $50 \%$ de las pretensiones del demandante, para "garantizar las resultas del proceso".

Con sano criterio, se debe acotar que el artículo 85 A del CPTSS sólo enumera de forma clara o taxativa, exclusivamente una medida cautelar, la cual se torna deficiente para lograr tutelar pronta y efectivamente el derecho sustancial del demandante mientras el juez dicta la sentencia. En este sentido, el ordenamiento laboral no contempla un amplio catálogo de medidas cautelares de las cuales pueda disponer el demandante para proteger su derecho mientras el juez dicta la sentencia.

Para reforzar lo anotado, es prudente resaltar que uno de los fines del Estado Social y Democrático de Derecho, es el de garantizar la efectividad de las prerro- 
gativas ius-fundamentales y la debida administración de justicia. En este contexto, no es desatinado llegar a pensar que las cautelas innominadas que el Código General del Proceso en adelante (CGP) precisa en su artículo 590, numeral 1, literal c, se podrían aplicar en el ordenamiento procesal laboral; máxime si se tiene como premisa, que la esencia de un proceso judicial se afinca en ofrecer una alternativa eficaz para garantizar la existencia del derecho sustancial ${ }^{1}$.

Para tales efectos, en los procesos ordinarios laborales se podría acudir al CGP, atendiendo al carácter residual del mismo y al fundamento del artículo 145 del CPTSS, que entroniza la aplicación analógica.

No obstante, con el fin de armonizar el procedimiento laboral, es indispensable un debido desarrollo normativo sobre el particular, a efectos de permear de seguridad legal el decreto de las cautelas innominadas en asuntos de esta especialidad; toda vez que, si en materia laboral se acude a la aplicación analógica de la ley para aplicar una medida cautelar innominada, el operador judicial se encuentra en una encrucijada de cara al principio de gratuidad (artículo 39 CPTSS).

Con la finalidad de decretar una medida cautelar innominada en procesos laborales, el demandante debe incurrir en el pago del veinte por ciento (20\%) del valor de las pretensiones (Art. 590, numeral 2 del CGP), y pese a que el juez puede aumentar o disminuir el monto de la caución, el hecho de que el demandante incurra en una erogación, por mínima que sea, va en contravía del principio de gratuidad.

Sin embargo, se debe tener presente que el ordenamiento laboral es garantista y vela por la protección de la parte más débil en las relaciones laborales, y esta premisa se constituye en la piedra angular del principio de la gratuidad. Conviene añadir que el juez laboral, mediante un prudente raciocinio, debe ponderar si opta por optimizar el principio de gratuidad (no decretando una medida cautelar innominada) o el de tutela jurisdiccional efectiva (decretando la medida cautelar innominada).

Justo en este contexto, emerge como pregunta de investigación la siguiente: ¿Por qué se garantiza la tutela jurisdiccional efectiva al incorporar las cautelas innominadas en el proceso laboral colombiano?; para dar respuesta al mencionado interrogante, se planteó como objetivo general: Determinar los argumentos que presentan a las cautelas innominadas como un instrumento procesal laboral que garantiza la tutela jurisdiccional efectiva.

$1 \quad$ BONETT ORTÍZ, Samir Alberto. "Incidencia del Código General del Proceso en el proceso laboral. Medidas cautelares". En Memorias XXXV Congreso Colombiano de Derecho procesal. Bogotá: Universidad Libre e Instituto Colombiano de Derecho Procesal, 2014, pp. 627-646. 
Con miras a desarrollar lo esbozado, se adoptó un diseño metodológico desde el enfoque socio-jurídico, bajo el paradigma dominante cualitativo, puesto que se debe describir, comprender e interpretar la regulación de las cautelas innominadas, en materia procesal laboral, a partir de la conceptualización de los teóricos clásicos y contemporáneos. Aplicando el método teórico deductivo y de análisis en el desarrollo de cada acápite, siguiendo el sendero de la investigación descriptiva y propositiva; por cuanto se empleó la teoría como un marco de referencia y un elemento esencial para justificar la adopción de las cautelas innominadas del CGP en un ordenamiento tan especial como el laboral.

\section{Tutela jurisdiccional efectiva de cara al decreto de medidas cautelares}

La afirmación del armazón procedimental, se mide en criterios de contundencia, transparencia, celeridad e innovación como herramienta de cambio social. Se infiere de lo anterior, que el arte de administrar justicia, supone la consumación de una serie de actos formales que conduzcan a la preservación de la armonía de la comunidad, ofreciendo la certidumbre y satisfacción de los derechos subjetivos.

En esta línea de pensamiento, es pertinente destacar que un régimen de justicia garante de los Derechos Humanos, debe contar con una arquitectura procesal que logre suplir las necesidades del entorno social, respondiendo efectivamente a los requerimientos y exigencias que día a día se presentan. En este sentido, el sistema procedimental debe implementar técnicas y métodos dúctiles, que eviten a toda costa la transgresión al debido acceso a la justicia, siendo este un derecho de rango ius-fundamental, preconizado en el artículo 229 de la Constitución Política de 1991.

Simultáneamente, se advierte que del derecho a la administración de justicia se deriva el de la "tutela jurisdiccional efectiva", definida esta, como una prerrogativa que permite anteponer la realización de un derecho sustancial sobre el propio ritualismo.

Ofrecerle al ciudadano la posibilidad de que sus pretensiones sean oídas y puestas en consideración, en símil sentido, que existan las debidas garantías procesales para que el derecho sustancial objeto de litigio no sea desconocido y vulnerado, auspicia el desarrollo de un sistema democrático, que tiene como bandera la satisfacción de las necesidades sociales y el dinamismo estructural en pro de la materialización de la justicia.

Paralelamente, conseguir el logro de los fines estatales, lleva inmerso el diseño de mecanismos sumarios y adecuados en materia jurisdiccional, para que 
de esta manera se proyecte el desarrollo y el progreso del conglomerado social en la efectividad de las decisiones judiciales; las que deben estar cimentadas por una Constitución Política viviente que promueva la atención sensible a los requerimientos sociales. Justo allí, es donde surge el venerado concepto de tutela jurisdiccional efectiva, esta se convierte en mediadora para que primen las garantías fundamentales sobre la integridad de la plataforma procedimental.

En efecto, el amparo judicial implica el ejercicio de los derechos subjetivos, especialmente en el cuidado que debe tener el juzgador para ser fiel observador de los criterios constitucionales; sobre estos predicamentos, debe proferir una decisión ceñida a lineamientos equitativos y garantes del espectro humanista.

Desde este horizonte, el CGP (Art. 2), precisa el derecho que se tiene a una tutela jurisdiccional efectiva, es decir, la prerrogativa con la que cuentan las personas para el pleno ejercicio de sus derechos sustanciales y la custodia de sus intereses, refugiándose en el gendarme del debido proceso con duración prudencial. Así las cosas, los términos y actuaciones deben tener como brújula el acceso a una justicia célere, inmediata, oportuna y efectiva.

Ha quedado evidenciado, que las contemporáneas arquitecturas procesales tienen como estandarte el acceso a la administración de justicia, estas propenden recobrar la arrebatada vitalidad y confianza en la jurisdicción y en la ley; por cuanto someramente se le ofrecía a los justiciables la posibilidad de poner un pie en falso en la maquinaria jurisdiccional, sin que realmente se les diera vía libre para conseguir el resguardo del derecho sustancial reclamado.

La Corte Constitucional al referirse a las cautelas innominadas, cita al jurista Rangel Romberg, para acotar que:

Las medidas innominadas son aquellas que no están previstas en la ley, dada la variedad de circunstancias que se pueden presentar y hacen dificil que sean contempladas todas por el legislador, que pueden ser dictadas por el juez acorde con su prudente arbitrio, para "prevenir que pudiera quedar ilusoria la ejecución del fallo o cuando hubiera fundado temor de que una de las partes pueda causar lesiones graves o de difícil reparación al derecho de la otra"2.

Para que proceda el decreto, tanto de las medidas cautelares que se encuentran preconizadas en el ordenamiento normativo, así como las medidas cautelares genéricas, se deben reunir una serie de requisitos. Estos tienen como razón de ser el brindar garantías a los sujetos procesales, en la eventualidad que con la aplicación de estas cautelas pueda generar un daño o una flagrante violación de sus derechos fundamentales, particularmente al debido proceso, porque son adoptadas con antelación al pronunciamiento definitivo del juez.

2 COLOMBIA. Corte Constitucional. Sala Plena. Sentencia C-835/13. Bogotá, D.C., noviembre 20 de 2013. MP. Nilson Pinilla Pinilla. Expediente D-9626. 
Por conducto de la Sentencia C-925/99 el Honorable Magistrado Naranjo Mesa, dilucidó la utilidad de las medidas cautelares para preservar el derecho objetivo de las personas que activan el aparato jurisdiccional, precisando la existencia del vínculo inherente entre las cautelas, el acceso a la justicia y la legitimidad; de este modo,

(...) para conservar su legitimidad, las normas procedimentales que se expidan deben estar cimentadas en criterios de proporcionalidad y razonabilidad, pues sólo la coherencia y equilibrio del engranaje procesal permite la efectiva aplicación del concepto de justicia y, (...) hace posible el amparo de los intereses en conflicto ${ }^{3}$.

Para concluir, es preciso traer a colación la Sentencia C-431/95, en la cual, grosso modo se dejó por sentado la esencia de la función cautelar, como herramienta del acceso a la justicia, la salvaguarda del derecho sustancial sobre el adjetivo y la satisfacción provisoria de los intereses preconizados en las pretensiones, de ahí que las cautelas adquieran "un carácter típicamente instrumental y provisional, en cuanto a su vigencia, aunado a su naturaleza jurisdiccional".

\subsection{Situación de las cautelas en los procesos ordinarios laborales con relación a la tutela jurisdiccional efectiva}

En lo que respecta el andamiaje de cautelas inserto en el ordenamiento procesal laboral, específicamente en los procesos ordinarios (declarativos); de la lectura íntegra del artículo $85 \mathrm{~A}$ del CPTSS se deduce que en el caso de los procesos declarativos (ordinarios laborales), el legislador sólo previó una medida cautelar, que es el pago de una caución a cargo del demandado, que tiene como extremos el $30 \%$ y el $50 \%$ del valor de las pretensiones del demandante.

Ello deja entrever que esta cautela taxativa es ínfima, precaria y deficiente, especialmente porque propende salvaguardar parcialmente el derecho sustancial que se debate en juicio; el monto de la caución deja desprotegida buena parte de las pretensiones, en algunos casos el 70\%, en otros el $50 \%$ de las mismas, es decir, no garantiza la debida tutela jurisdiccional efectiva del derecho material del demandante.

Ante esta circunstancia, es ventajoso aseverar que es irrisible que el legislador en este artículo se jacte de "garantizar las resultas del proceso", verbigracia, asegurar una eventual sentencia; cuando a todas luces abre una brecha para que la parte demandada se insolvente, y de esta manera, no se garantice una

3 COLOMBIA. Corte Constitucional. Sala Plena. Sentencia C-925/99. Santafé de Bogotá, D.C., noviembre 18 de 1999. MP. Vladimiro Naranjo Mesa. Expediente D-2407.

4 COLOMBIA. Corte Constitucional. Sala Plena. Sentencia C-431/95. Santa Fé de Bogotá, D.C., septiembre 28 de 1995. MP. Hernando Herrera Vergara Expediente. D-870. 
completa tutela de los derechos sustanciales del demandante a través de una sentencia que sea efectiva, en términos de realización de derechos.

\section{La función cautelar del administrador de justicia desde la verosimilitud del derecho sustancial}

\subsection{La figura del gran juez y director del proceso}

Sócrates entronizaba la figura del juez en un catálogo de virtudes, que estructuraban lo ecuánime, desde la mirada benigna de un ser que escucha cortésmente, responde sabiamente, pondera prudentemente y decide imparcialmente. Trasformando el anaquel de las sempiternas dudas, en argumentos que se irradian por el matiz de la efectividad de la justicia, y el ritual de las garantías inherentes a la dignidad humana. En palabras de Carnelutti: “(...) es verdad que la ciencia del bien y del mal es fruto prohibido a los hombres; pero precisamente por eso el juez debería ser más que un hombre y pedir a Dios la gracia de superar su humanidad (...)"5.

El asiduo de circunstancias que trasgreden las prerrogativas fundamentales, ha incentivado el surgimiento de instrumentos, técnicas y/o enfoques jurídicos, que propenden ser la amalgama idónea entre el medio y el fin. Al funcionario investido de jurisdicción, se le endilga la obligación de tutelar efectivamente los derechos que asumen la connotación de sustanciales, y al mismo tiempo, ser respetuoso de las formas propias de cada actuación judicial. Según Von Ihering: El derecho es una idea práctica, es decir, indica un fin, y como toda idea de tendencia, es esencialmente doble porque encierra en sí una antítesis, el fin y el medio. No basta investigar el fin, se debe además mostrar el camino que a él conduzca. (... .6.

A la postre, emerge el concepto de proceso judicial, que se finca en pilares metodológicos y sistemáticos para la efectividad y resguardo de los Derechos Humanos, como quiera que establece la unión indisoluble con una serie dinámica de actos jurídicos de índole procedimental?

La integridad judicial colombiana, paulatinamente ha asumido el reto de ser garante de los derechos constitucionales, que enarbolan el Estado Social y Democrático de Derecho; premisa bajo la cual, la arquitectura normativa ha hecho suyo el propósito de formar jueces que tengan como prioridad la

5 CARNELUTTI, Francesco. Cómo nace un proceso. [Santiago Sentís Melendo y Marino Ayerra Redín, Trad.]. Segunda edición. Bogotá: Editorial Temis S.A. Monografías Jurídicas No 56, 2002, p. 71.

6 VON IHERING, Rudolph. La lucha por el derecho. Bogotá: Editorial Temis S.A. Monografías Jurídicas No 72. 2000, p. 3.

7 CALVINHO, Gustavo. La procedimentalización posmoderna. En: Revista del Instituto Colombiano de Derecho Procesal. Bogotá D.C: No 39, 2013, p. 11. 
armonización de los derechos fundamentales, y la interpretación de compendios legales que ofrecen herramientas de raigambre constitucional. Es por ello que, “(...) para orientarse en el laberinto de los códigos, el juez no solo debe tener un conocimiento profundo de ello, sino que debe poseer la perspicacia que le permita captar de una mirada la semejanza entre el hecho que ha conseguido establecer y la hipótesis, es decir el caso previsto por la ley (...)"'. En palabras del maestro Parra Quijano, “(...) el juez es cada día más idóneo para saber qué se necesita para proteger un derecho (...."'.

La prevalencia del interés general en el Estado Social y Democrático de Derecho, convierte al juez de manera automática en garante de la efectividad de la justicia material. El conjunto armónico de las actuaciones jurisdiccionales se direcciona en procura de la rápida y cumplida justicia, debido a que las formas propias del proceso deben servirle de catapulta al derecho sustancial; garantizando con ello condiciones fundadas en la dignidad humana y en el acceso igualitario a la administración de justicia. Máxime, si se tiene como directriz, el debido proceso; permitiendo que todo individuo que se vea inmerso en cualquier tipo de actuación judicial, goce de garantías que le permitan buscar la imparcialidad y evitar la arbitrariedad y, por ende, obtener un resultado enmarcado dentro de la equidad y la justicia.

El ejercicio y la aplicación del derecho al debido proceso, exige que las actuaciones adelantadas por los funcionarios que administran justicia, se vislumbren desde la guarda del respeto pleno por la normatividad vigente y por los procedimientos establecidos en el marco jurídico, aplicando la ley sustancial y procesal; ofreciendo al individuo la potestad de que sus pretensiones sean oídas y tenidas en cuenta, de aplicar el principio de contradicción, de ejercer plenamente y sin dilaciones su defensa, y ante todo, preservar el derecho sustancial que pretende hacer valer en juicio.

La autonomía de los jueces en la toma de decisiones, se estructura de la base de la perspectiva axiológica de la imparcialidad, partiendo del supuesto que desde la óptica de la administración de justicia el operador jurídico queda investido de juridicidad, para proceder con inclinación a la justicia, cotejándose a la luz de las garantías fundamentales.

El juez en el CGP, asume un rol preponderante en el desempeño de funciones que penden de un componente actitudinal, por cuanto le es entregada la potestad de ser un "gran juez" director de la actuación; facultad que se convierte en la llave

8 CARNELUTTI, Francesco, 2002. Ob. cit., p. 73.

9 PARRA QUIJANO, Jairo. Medidas cautelares en el Código General del Proceso. En Forero Silva, Jorge (prólogo). Primera edición. Bogotá: Pontificia Universidad Javeriana: Editorial Temis. 2013. 
maestra para abrirle paso a la "tutela jurisdiccional efectiva" estatuto procesal, fue creado para un juez acucioso, coherente y con amplia capacidad de razonamiento, de tal suerte, que se convierta en impulsor de la legitimidad más no de la parcialidad.

El juez que pronuncia sus decisiones y cumple sus deberes funcionales diligentemente dentro de los plazos legales, podrá ser considerado activo; será "activista" si, además, a partir de una visión progresista, evolutiva, reformadora, sabe interpretar la realidad de su época y le confiere a sus decisiones un sentido constructivo y modernizador ${ }^{11}$.

El apremio por suplir las necesidades de la justicia, con el pasar del tiempo ha devuelto a los jueces el poder que le fue arrebatado por el legislador, un poderío que trastoca en un ámbito más amplio y discrecional de la facultad jurisdiccional; el poder de darle vida al derecho, que otrora se dejó extinguir, devuelve la credibilidad en un régimen de justicia, que responde a los requerimientos sociales. Entronizando al proceso judicial bajo los postulados de efectividad, ductilidad, coherencia, salvaguarda y ante todo respeto a la labor del funcionario que en algún tiempo asumió el rol de espectador y aplicador mecánico de la panacea legal.

Con la finalidad de comprometerse con la salvaguarda y respeto de los límites de la potestad legislativa, la Corte Constitucional colombiana ha dejado por sentado mediante la Sentencia C-227/09, en correspondencia con las Sentencias C-728 de 2000, C-1512 de 2000, C-1104 de 2001 y C-426 de 2002, que el legislador al proferir normas procesales, de ninguna manera debe despojar arbitrariamente al juez de las facultades que se le han conferido para la protección de los derechos sustanciales llevados ante la instancia judicial; debiendo expedir una normatividad, que en primera medida vaya en consonancia con la axiología y los fines del Estado Social de Derecho; en un segundo estadio, que abandere la vigencia del orden justo y la primacía de los derechos fundamentales al interior de un proceso judicial; como tercer ítem, la utilización de los criterios de razonabilidad y proporcionalidad en el despliegue procesal; finalmente, que garantice la superioridad y la optimización del derecho sustancial sobre el adjetivo.

Los lustros del positivismo han inculcado una cultura jurídica que se dedica a imponer el imperio absoluto de preceptos rígidos y ritualistas, en su

10 CANOSA SUÁREZ, Ulises. Código General del Proceso. Propósitos. Bogotá: Secretaría General, ICDP. 2012.

11 BERIZONCE, Roberto Omar. Activismo judicial y participación en la construcción de las políticas públicas. En Revista Virtual Del Instituto Colombiano de Derecho Procesal No 36. 2010, p. 21: Recuperado el 18 de junio de 2014; de [www.icdp.org.co/revista/ articulos/36/Roberto\%20Omar\%20Berizonce.pdf]. 
mayoría, desconocedores de la eficacia material de los Derechos Humanos como desarrolladores del principio rector de la dignidad humana. No obstante, el protagonismo del juez que se preocupa por la tutela jurisdiccional efectiva, debe afincarse en lineamientos mesurados y meticulosos, a fin de conservar la vitalidad de la imparcialidad y el orden igualitario, tal como lo estima la Corte Constitucional mediante las Sentencias C-925 de 1999 y C-203 de 2011.

\subsection{La integridad y activismo judicial con ocasión al decreto de medidas cautelares innominadas}

Las partes son quienes introducen al proceso la posibilidad de encriptar las pretensiones, mediante cautelas que vislumbran las sendas de la conservación del derecho que se persigue; correlativamente, activa el actuar oficioso de un juez que encarna un ápice de inquisitivo. En virtud del CGP y de la Carta Política, el juez en principio se convierte en garante del acceso a una justicia rápida y diligente. Según lo preconizado en el artículo 590, numeral 1, literal c del CGP, el juez haciendo uso de facultades discrecionales, cierra las brechas de la duda y de la desazón que ha producido el extrapolado positivismo draconiano.

Respecto a la discrecionalidad del juez al aplicar una medida cautelar atípica, la Corte Suprema de Justicia, ha puesto de manifiesto que se constituye en una sana práctica el acudir a la hermenéutica jurídica para decidir cuál es la cautela más razonable para el caso en concreto, "(...)además, según lo ha expresado esta Corte, (...) independientemente de que se comparta o no la hermenéutica de los juzgadores atacados, ello no descalifica su decisión ni la convierte en caprichosa y con entidad suficiente de configurar vía de hecho (...)"”l2.

Las medidas cautelares innominadas facultan al administrador de justicia para que acuda a criterios de razonabilidad y proporcionalidad en el momento de decretar una cautela diferente al catálogo establecido en la normatividad: “(...) Así, aunque las medidas cautelares innominadas no significan arbitrariedad, sino una facultad circunstancialmente atribuida al juez técnicamente para obrar consultando la equidad y la razonabilidad, al servicio de la justicia, los parámetros para su imposición se encuentran previamente establecidos en la ley"13.

En suma, el juzgador activo, se refugia en la hermenéutica y en las reglas de la lógica para hilvanar decisiones que prohíjan al "debido proceso" (art.29

12 COlOMBiA. Corte Suprema de Justicia. Sala de Casación Civil. ST.C2343-2014. Bogotá, D. C., febrero 27 de 2014. MP. Luis Armando Tolosa Villabona. Radicación No. 11001-02-03-000-2014-00342-00.

13 Ibídem. 
$\mathrm{CP})$, como brújula de su actuar; aspecto que esgrime un meticuloso control de legalidad y de constitucionalidad, en lo tocante a las cautelas innominadas, que, bajo el literal c, del numeral 1, del artículo 590 del CGP, se pusieron a su entero servicio.

Contrario a lo que se pueda llegar a pensar, al enriquecer el abanico de las medidas cautelares, se han aniquilado las excusas de un anacrónico sistema y un régimen judicial moroso en la tutela efectiva de los derechos sustanciales. Quién mejor que el juez para conocer de cerca las necesidades de la sociedad que acude a los estrados judiciales con el anhelo de no dejar esfumar sus pretensiones, es él quien puede adecuar los instrumentos legales para la prevalencia del tan ansiado orden justo.

La justicia es como una roca situada en la cima de un monte: el hombre no tiene alas para llegar hasta allá volando; lo único que puede hacer es abrirse paso fatigosamente hacia ella escalando las laderas; y a menudo se extravía y se destroza las manos. Lo que lo guía, lo que lo atrae, lo que lo eleva, es la belleza de aquella cumbre que resplandece a lo lejos. La fuerza que le sirve para subir, es la razón; y él llama razón a cada paso que da en su camino. El sentido de la justicia, que posee innato en su corazón, se refracta, como la luz a través de un prisma, en mil colores; cada rayo que le llega de aquella fuente, es la razón (.... $)^{14}$.

Quien acude ante el juez para confiarle sus pretensiones, le está entregando un derecho que puede perder su vitalidad por causa de la solidez de la arquitectura procesal, que ha sido impuesta por un legislador que no conoce de cerca las necesidades del régimen de justicia; razón por la cual, es atinado devolverles lo que otrora se le esfumó fugazmente entre la paquidermia de un compendio legal elaborado por los parlamentarios. Cabe aclarar que no se desconoce el rol fundamental del parlamentario dentro del Estado de Derecho, empero, hay dejar de presente que es necesario que el legislador le permita al funcionario judicial un mayor desenvolvimiento, permitiéndole adoptar las herramientas adecuadas para solventar las controversias; de modo tal que el andamiaje jurídico se enriquece en la medida en que tanto el legislador como el funcionario judicial trabajan sinérgicamente, por una parte el legislador cumple con su labor de regular, pero al mismo tiempo hace posible que el funcionario judicial sea activo y acuda a su sana crítica y hermenéutica adecuando y encontrando soluciones a los requerimientos de las partes. Así las cosas, en juez deja de ser asumido como un simple espectador y ejecutor de inertes disposiciones, para convertirse en un ilustrado, inquieto y justo juez.

14 CARNELUTTI, Francesco, 2002. Ob. cit., pp. 70-71. 


\subsection{Juicio de verosimilitud y necesidad: "fumus boni iuris" - "periculum in mora}

En esta materia, la Corte Constitucional en Sentencia de Unificación SU $447 / 11^{15}$, desarrolla lo acotado por las Sentencias C-490/00, C-485/03, C-379/04 y C-039/04, esbozando que el legislador está investido de soberanía legislativa; así las cosas, tiene la facultad de regular libremente lo correspondiente a las medidas cautelares. Sin embargo, se le impone en esta materia el deber de cuidado, toda vez que las mismas tienen esencialmente su radio de acción antes de que el demandado sea derrotado mediante una sentencia en firme. En el evento en que el legislador y el operario judicial viabilicen la aplicación de las cautelas de manera indiscriminada, se pueden conculcar derechos fundamentales al demandado, más aún si se parte del hecho de que no ha sido vencido en juicio.

A criterio de la Honorable Corte Constitucional, los mecanismos cautelares tienen un trasfondo preventivo y asegurador, lo primero para evitar eventuales perjuicios o la pérdida del derecho que se discute, y frente al segundo efecto, asegura la eficacia de las decisiones judiciales. Por las anteriores razones, es tan importante que se actúe bajo la directriz del derecho a la defensa y la guarda al debido proceso.

A raíz de la tensión que se ha derivado de la aplicación de los instrumentos cautelares, ha sido necesario establecer presupuestos para su aplicación y que los mismos, cumplan el rol de evitar la claudicación de los derechos del demandado, al ser objeto de aplicación de determinada medida cautelar.

La Corte Constitucional esboza dos componentes del decreto de medidas cautelares, y estos son: la apariencia de un buen derecho "fumus boni iuris" y el peligro en la demora "periculum in mora"16, los cuales influyen en el momento en que un juez hace el juicio de razonabilidad y proporcionalidad para la aplicación de determinada medida cautelar. Como se vislumbra en algunas sentencias como la SU-913/09; el primero, tiene que ver con la verosimilitud de la afectación del derecho sustancial, es decir, la existencia de una afectación flagrante de la prerrogativa; por otra parte, el peligro de la demora hace referencia a el paso del tiempo y las consecuencias nocivas para el derecho sustancial alegado en las pretensiones, que repercutiría indefectiblemente en la efectividad o materialización de la misma sentencia.

A través de la Sentencia C-523/09 se conceptualizó que las medidas cautelares tienen fundamento constitucional, por cuanto son tendientes a

15 COLOMBIA. Corte Constitucional. Sala Plena. Sentencia SU.447/11. Bogotá, D.C., mayo 26 de 2011. MP. Mauricio González Cuervo. Expedientes T-2.089.121 y T-2.180.640 (acumulados).

16 Ibídem. 
proteger el resultado de una eventual sentencia; dado que, de no ser aplicadas en el momento oportuno podrían repercutir en la extinción del derecho sustancial objeto de litigio y de igual forma, desequilibrar la actuación procesal; “(..) tienen por objeto garantizar el ejercicio de un derecho objetivo, legal o convencionalmente reconocido, impedir que se modifique una situación de hecho o de derecho o asegurar los resultados de una decisión judicial o administrativa futura, mientras se adelante y concluye la actuación respectiva(...)"17.

El juez de ninguna manera puede obviar que la iniciativa para decretar medidas cautelares innominadas debe provenir de la parte legitimada, que al evidenciar la existencia de riesgo o amenaza con la duración de la actuación procesal -periculum in mora ${ }^{18}$, debe acudir ante el funcionario para pedir la protección de su pretensión, indicando la medida que ha estimado pertinente. Consecuencialmente, el juez queda investido de la facultad para decretarla, si logra tener un primer acercamiento verosímil con el derecho, a lo que la doctrina ha denominado "apariencia de buen derecho" - fumus bonis iuris.

El decreto de las medidas cautelares no puede hacerse depender de la certeza sobre la existencia del derecho subjetivo por el demandante en el proceso principal; ello sería absurdo por imposible, pues el proceso principal, al que sirve la medida cautelar, carecería entonces de razón de ser. Desde el principio contrario, el decretar las medidas no debe hacerse ante la mera solicitud del demandante; es necesario que el derecho alegado ofrezca indicios de probabilidad, que el demandante ha iniciado el proceso con "seriedad", que existe cuando menos una "apariencia de buen derecho".

Desde esta óptica, el fundamento de las medidas cautelares aparece, así como un término medio entre la certeza, que establecerá la sentencia en el proceso principal, y la incertidumbre, base de la iniciación de ese proceso; ese término medio es la "verosimilitud". Los problemas surgen a la hora de determinar caso por caso cómo se acredita ese fumus bonis iuris. En ocasiones las leyes exigen que

17 COLOMBIA. Corte Constitucional. Sala Plena. Sentencia C-523/ 09. Bogotá, DC., agosto 4 de 2009. MP. María Victoria Calle Correa. Expediente D-7612.

18 FLÓREZ GACHARNÁ, Jorge. Los actos procesales de cautela en el proceso judicial dentro del estado social de derecho. En: Revista Virtual del Instituto Colombiano de Derecho Procesal No. 35 - 2009. Recuperado: el 18 de junio de 2014. De [http://www. icdp.org.co/revista/articulos/35/Jorge\%20Florez\%20Gacharna.pdf].

Según Flórez: El perículum in mora básico de las medidas cautelares, no es el peligro de daño genérico jurídico, al cual se atiende mediante los dos procesos clásicos, sino el peligro específico derivado de la duración de la actividad jurisdiccional, considerada en sí misma como posible causa de un ulterior daño; mientras que el daño ya causado encuentra su remedio en los procesos declarativo y ejecutivo, las medidas cautelares tratan de evitar que ese daño se agrave como consecuencia de la duración de aquéllos. 
con la demanda del proceso principal se acompañe un principio de prueba por escrito o un documento del que resulte de la existencia del derecho reclamado ${ }^{19}$.

Paralelamente, el funcionario debe percibir con objetividad la necesidad de adoptar determinado instrumento cautelar, que debe reunir como presupuesto la proporcionalidad. Es prudente resaltar, que después de que la parte interesada ha puesto en actividad al juez con la solicitud de la medida cautelar, quien, haciendo uso de sus facultades oficiosas, puede variar, alterar o suspender la medida cautelar decretada.

Son pues, la expresión de un poder cautelar general, reconocido al juez en este campo, con el fin de que pueda proveer -sin las limitaciones que le impone el tradicional sistema de las medidas cautelares nominadas - a la mejor escogencia de los medios para asegurar el resultado procesal y de ejecución a que aspira una de las partes ${ }^{20}$.

$\mathrm{Al}$ vislumbrarse la apariencia de buen derecho -fumus bonis iuris-, el juez hace una abstracción mental, que le permite tener la primera aproximación con la realidad prima facie, contexto que es estimulado por actos de representación pre-probatorios. En consecuencia, las elucubraciones del funcionario, provienen de su razón práctica y del orden normal de las cosas. Carnelutti, hace alusión a ello, cuando afirma que:

En la idea la imagen y el concepto son como la impresión en la moneda. Hay un concepto sin idea y una idea sin concepto: el primer caso sucede cuando el concepto está todavía in mente hominis y el pensamiento no ha llegado a ser idea, más bien que en el concepto consiste una imagen. Por eso no es cierto que el concepto sea la forma sino solo una forma de la idea ${ }^{21}$.

Razón por la cual, las medidas cautelares innominadas son catalogadas como instrumentos idóneos que hacen las veces de garantía provisional, en casos excepcionales, su finalidad es procurar por la efectividad de la futura decisión judicial, ostensiblemente se direccionan a materializar el acceso a la justicia, en virtud de satisfacer los intereses de la parte que se encuentra legitimada para solicitarla y, que descubre en el andamiaje jurídico, una ventana por la cual puede ingresar la protección de su derecho, que se debe resguardar de una forma diferente a la contemplada por el legislador en el acápite de medidas cautelares tradicionales.

19 Ibídem.

20 RENGEL ROMBERG, Aristides. Las medidas cautelares innominadas. En Revista Virtual del Instituto Colombiano de Derecho Procesal No 20. 1996, p. 91. Recuperado el 18 de junio de 2014, de [http://www.icdp.co/revista/articulos/8/MADIDAS\%20CAUTELARES\%20 INNOMINADAS-\%20ARISTIDES\%20RANGEL\%20ROMBERG.pdf].

21 CARNELUTTI, Francesco. Metodología del Derecho. [Santiago Sentís Melendo y Marino Ayerra Redín, Trad.]. Bogotá: Editorial Temis S.A. Monografías Jurídicas N 17. 2011, p. 56. 
En síntesis, es beneficioso acotar que, al administrador de justicia, se le endilga el poder-deber de hacer prevalecer el derecho sustancial sobre las formas propias de la solidez procesal; haciendo uso de la hermenéutica tiene la potestad de realizar un juicio de razonabilidad y proporcionalidad, sobre la adecuación de los instrumentos idóneos aplicables al caso en concreto, para tutelar sumaria y provisionalmente un derecho verosímil, en procura del aseguramiento de una eventual sentencia.

\section{De lo taxativo a lo razonable: decreto de cautelas innominadas en laboral}

\subsection{Desde lo legal y taxativo hasta su ductilidad a la razonabilidad}

La postura de hacerle culto al positivismo y al ritualismo legalista, finalmente se ha transformado en la bayoneta de un legislador que usurpa o mengua la injerencia del juez, a quien se le ha despojado de la posibilidad de realizar juicios de razonabilidad, para los casos en que la ley no salvaguarda en debida forma la justicia material, contexto que el honorable jurista Parra Quijano resume en una frase: “(...)nunca debió el legislador usurpar el oficio del juez regulando todas las llamadas medidas cautelares, ya que hay situaciones que sólo el juez las puede entender y concretar (...)"22.

El debate jurídico sobre el principio de legalidad y taxatibilidad en materia de medidas cautelares, ha sido un tema que decanta diversas posturas, en el caso particular del jurista Restrepo Medina, sostenía que el juez no debía limitarse a un catálogo de cautelas, a sabiendas de que ninguna de ellas ofrecería la salvaguarda provisional del derecho sustancial, por ende, atizó en la posibilidad de cambiar de paradigma y apostarle al concepto de medidas cautelares innominadas o atípicas.

(..) resulta insuficiente la regulación actual de la tutela cautelar judicial, concebida en forma taxativa, de manera que solamente tienen carácter cautelar aquellas medidas establecidas mediante una regla jurídica. (...) resalta por su ausencia una previsión legislativa de carácter general que permita al juez el decreto de medidas cautelares atípicas o innominadas, a efecto de garantizar con el mayor grado posible de certeza la eficacia de la sentencia. (...) ya que una orden plasmada en el papel sin que se logre ejecutar, deja intacta la situación de vulneración de los derechos que se pretenden proteger ${ }^{23}$.

22 PARRA QUIJANO, Jairo. Medidas cautelares innominadas. En Memorias XXXIV Congreso Colombiano de Derecho Procesal. Bogotá: Universidad Libre de Colombia e Instituto Colombiano de Derecho Procesal. 2013, p. 302.

23 RESTREPO MEDINA, Manuel Alberto. Perspectiva constitucional sobre la tutela cautelar judicial. El caso colombiano. Saberes- Revista de estudios jurídicos, económicos 
El culto a la ley ha repercutido negativamente en el desarrollo y progreso del régimen de justicia, en tema de medidas cautelares, la taxatibilidad despoja al juez de la posibilidad de realizar un juicio de razonabilidad para determinar la procedencia, el alcance y el tipo de medidas precautorias idóneas, que se puedan adoptar si se llega a vislumbrar el humo del derecho reclamado por el demandante, que en palabras de algunos estudiosos juristas, asume la denominación de "apariencia de buen derecho".

En el caso de las medidas cautelares innominadas, al juez se le devuelve el aditamento actitudinal; por ello, tiene la obligación de realizar un acucioso juicio de razonabilidad, motivando su decisión en aspectos como la utilidad, la pertinencia, la necesidad, la urgencia y la ausencia de una medida cautelar adecuada.

Atendiendo a su razón instrumental, el rigorismo procesal ha dispuesto que las cautelas deben atender el criterio rector de la taxatibilidad, para garantizar el pleno desenvolvimiento del principio basal de legalidad, circunstancia que le ha menguado potestades a un juez que en algún momento histórico fue inquisitivo; ello ha ofrecido la posibilidad de generar seguridad jurídica y coherencia sistémica a la función judicial.

No obstante, el derecho es dinámico y de ningún modo debe sujetarse a criterios estáticos e injustos, de ello se puede inferir que para poner en funcionamiento un régimen de justicia garante de los derechos sustanciales, se debe abrogar la tesitura que encuadra la tutela judicial efectiva con el gramaticalismo draconiano. Si bien, el funcionario investido de jurisdicción está sometido al imperio de la ley, también está en la obligación de darle sentido al derecho positivo, de darle razón a la existencia de la arquitectura normativa y de ser un facilitador de instrumentos eficaces; todo ello es posible si se redefine la ideología exegética que aún predomina en muchos juristas.

Es preciso agregar que el criterio de taxatibilidad es necesario para mantener el gendarme del poder de la ley y, correlativamente, el juicio de certeza, que conduce al concepto de seguridad jurídica, pero más que ello, lo verdaderamente necesario es que el juez tutele efectivamente los derechos, conforme a un andamiaje procesal que le permita ser más activo, pero de ningún modo parcial o ampliamente discrecional.

Por ello planteamos que, para que la equidad, sea más manifiesta, y la aquiescencia, con el derecho sustancial sea plausible, las medidas cautelares, no necesariamente deben ser taxativas. Tanto positivismo de lo jurídico, a veces se

y sociales. Volumen 4. Madrid-España:Universidad Alfonso X el Sabio Avda. Villanueva de la Cañada. Separata 1: 26. 2006, p. 20. Recuperado en junio 19 de 2014. De [http:// www.uax.es/publicacion/perspectiva-constitucional-sobre-la-tutela-cautelar-judicial-el-caso-colombiano.pdf]. 
transforma en gramaticalismo, y los jueces, no pueden llegar a fallar dentro de un contexto más amplio de horizontes y de miras, sino que deben supeditarse a principios cuyo rigor, a veces contradice la misma esencia de la justicia (... $)^{24}$.

El cambio paradigmático entre lo taxativo y lo razonable, acarrea el surgimiento de múltiples interrogantes que han generado apremio e incertidumbre; en vista de ello, es de vital importancia cerrar la brecha de una posible inseguridad jurídica que desnaturalizaría el poder imperativo del compendio legal.

No obstante, respecto al principio de legalidad, la Corte Constitucional mediante las Sentencias C-355/08, C-414/12, y C-851/13 básicamente precisan que el principio de legalidad es necesario para el despliegue del actuar de las autoridades públicas; empero, es imposible que todo lo regulado tenga un núcleo duro de significación amplio, a contrario sensu, muchos presupuestos hipotéticos (leyes-regulaciones) se caracterizan por tener una zona de penumbra considerable, en donde juegan un rol preponderante los principios orientadores del derecho, la sana crítica y la razonabilidad de quien tenga la función de administrar justicia en dado momento.

Indudablemente, a medida que la sociedad avanza, la arquitectura legislativa debe adaptarse a los nuevos requerimientos y dejar a un lado las estructuras o sendas antiquísimas que desdibujan la salvaguardia de las garantías y derechos de quienes habitan determinada nación, el admirado Chevallier, Citando a Timsit, expone que: "(...) el derecho posmoderno, se presenta como un derecho pragmático, basado en una voluntad de acción sobre la realidad; esta preocupación de eficacia modifica la concepción tradicional de la normatividad: la rigidez cede el paso a la flexibilidad, y la estabilidad, a la adaptabilidad. Este derecho aparece como un -otro derecho- (...)"25.

Desde esa arista, la configuración jurídica asume la imperiosa misión de focalizarse en proporcionar instrumentos lógicos y apropiados para cumplir con el verdadero fin de un Estado Social y Democrático de Derecho, que propende por mantener en alto las banderas de un esqueleto jurídico soportado en una columna vertebral compuesta por la tutela judicial efectiva, ello enhebra en el principio rector de la dignidad humana de quien confía en el juez como figura que encarna el régimen de justicia imperante.

En tal virtud, el conjunto normativo debe responder a las necesidades sociales, de no ser así, el juez está en el deber de buscar los instrumentos y vías jurídicas por las cuales pueda salvaguardar el cúmulo de garantías que se puedan

24 ROJAS GONZÁLEZ, Germán Eduardo. Esencia y trámite de la función cautelar. Primera Edición. Bogotá: Editorial Doctrina y Ley. 1996, p. 18.

25 CHEVALLIER, Jacques. El Estado posmoderno. [L'Etat post-moderne, tr Oswaldo Pérez]. Primera edición en castellano. Bogotá: Universidad Externado de Colombia. 2011, p. 237. 
ver transgredidas en el despliegue de un proceso, conservando el debido respeto por los pilares procesales imantados por la imparcialidad.

Llegando a este punto, la función cautelar con perspectiva innominada, está enmarcada en las facultades judiciales de un juez justo y coherente, que debe afianzar su criterio en argumentos razonados y referenciados por un acto de representación pre-probatorio, que le permita tener una primera aproximación con el derecho que la parte desea proteger mediante una cautela atípica. "(...) si observamos que aun careciendo un ordenamiento jurídico de una regla expresa al respecto, la doctrina y la jurisprudencia, una en la teoría y otra en la práctica, han reconocido la necesidad y la posibilidad de decretar medidas no previstas especialmente en la ley ${ }^{26}$.

Dentro de los grandes retos que enfrentan las medidas cautelares innominadas, está el miedo que embarga a los jueces de extralimitarse en sus facultades, no obstante, es prioritario derrocar las creencias tradicionalistas y forjadas en que la solución a los problemas jurídicos deben encontrarse preceptuadas, clara e inequívocamente, en un compendio legal, circunstancia que desvía el rol preponderante de un juez justo, a un funcionario que traslada normas a casos concretos, sin tener como prioridad la tutela judicial efectiva de los derechos sustanciales.

\subsection{Las cautelas innominadas del CGP como inspiración para el decreto de medidas en los ordinarios laborales}

Las medidas cautelares innominadas como alternativa para preservar los derechos sustanciales del demandante y el temor de los jueces de incurrir en una vía de hecho por aplicarlas, fueron algunos de los temas tratados en la sesión del 26 de enero de 2005, en la cual se reunió la Comisión Redactora del Código General del Proceso, conformada por los juristas: Ramiro Bejarano Guzmán, Jairo Parra Quijano, Pablo Felipe Robledo del Castillo y Miguel Enrique Rojas Gómez, miembros del Instituto Colombiano de Derecho Procesal.

Se precisó que:

El acceso a la justicia no puede ser considerado simplemente como un ingreso, que sería un criterio parasitario y burocrático, sino entendido como la acción de llegar a gozar de una justicia que tenga calidad y se concrete en una sentencia justa y pronta. (...) Acceder, implica tener el derecho a utilizar medidas cautelares suficientes para asegurar el cumplimiento real y efectivo de lo que se concrete en la sentencia. Obtener una sentencia, después de mucho esfuerzo, que no puede ser

26 PODETTI, Ramiro. Tratado de las medidas cautelares. Segunda edición. Buenos Aires: Editorial EDIAR. 1955, p. 62. Recuperado en junio 19 de 2014. De [http://venezuelaprocesal.net/Podettimedidas.pdf].

ISSN 2346-3473 • pp. 205-228 • Julio - Diciembre de 2017 • Bogotá, D.C. - Colombia 
satisfecha por insolvencia real o ficticia del obligado, genera una doble frustración, que evita que aquella a la larga se invierta en paz con justicia social ${ }^{27}$.

Según reza el artículo 590 del CGP en su numeral 1, literal c, en el caso de los procesos declarativos son procedentes cualquier medida cautelar que el juez considere apropiada y acertada, en aras de salvaguardar la efectividad material del derecho que se reclama, evitando que éste se torne ilusorio. Con ello, se incorporó la novedosa figura de "medidas cautelares innominadas" al estatuto procesal, que, en el caso de aplicarse, les debe anteceder la petición del demandante y deben ir acompañadas de una puntual motivación del juez, para apartar el peligro de abuso.

De igual forma, para decretar la medida cautelar atípica, el CGP en el mismo artículo bajo el numeral 2, preceptúa que el demandante debe prestar una caución equivalente al veinte por ciento (20\%) de las pretensiones, con la finalidad de ofrecer una garantía en caso de generar al demandado perjuicios o daños con la medida, circunstancia que de ninguna manera restringe el campo de acción para el juez, dado que, tiene la potestad de aumentar o disminuir el monto según sean las condiciones de apariencia de buen derecho.

De lo anterior, hay que hacerse la aclaración de que, en los asuntos de naturaleza laboral, prima el principio de la gratuidad, que está preconizado en el artículo 39 del CPTSS, y es por ello, que las cautelas innominadas que contempla el CGP, no son del todo compatibles con los postulados procesales laborales, en lo que respecta el pago de una caución por parte del demandante. Para solucionar definitivamente este bache, el deber ser es que exista la adecuada regulación por parte del legislador, quien tiene la facultad de armonizar la implementación de las medidas cautelares innominadas de manera particular y especial en el orbe laboral.

Sin embargo, mientras se materializa su debida regulación, el juez laboral podría decretar medidas cautelares innominadas (artículo 590, numeral 1, literal c del CGP) con fundamento en el artículo 145 del CPTSS, el cual permite la aplicación analógica de la ley; ello con la finalidad de garantizar la primacía de la tutela jurisdiccional efectiva. Y en lo tocante a la virtual vulneración del principio de gratuidad, a causa del pago de la caución que el demandante debe prestar, por el veinte por ciento (20\%) del valor de sus pretensiones, para el decreto de la medida cautelar innominada, se debe advertir que el juez en virtud de sus facultades hermenéuticas debe hacer una adecuada ponderación, para decidir si mediante el decreto de la medida cautelar innominada optimiza el principio

27 INSTITUTO COLOMBIANO DE DERECHO PROCESAL [ICDP]. Exposición de motivos del proyecto de Código General del Proceso. 2005. Recuperado en junio 28 de 2014, de [http://www.icdp.org.co/descargas/cgp/PresentacionCGP.pdf]. 
de tutela jurisdiccional efectiva, o si por el contrario, optimiza el principio de gratuidad al no decretar la medida cautelar innominada.

En caso de optar por la segunda opción, el operador judicial debe ser consciente de que si bien está "protegiendo" a la parte débil de la relación laboral, para que esta no incurra en erogación alguna, a la vez, esa "protección" es carente de sentido, cuando finalmente, el demandante observa como paulatinamente el derecho que alega se esfuma mientras dura el trámite procesal, y que finalmente, al obtener la sentencia, esta se queda en la esfera de lo abstracto, porque infortunadamente el derecho sustancial que se pretendía resguardar se ha desmoronado.

Bajo lo esbozado, a modo de conclusión se acota que el operario judicial es el encargado de materializar el ideal de justicia y equidad, así como velar por el verdadero acceso a la administración de justicia mediante mecanismos idóneos que permitan la salvaguarda de derechos sustanciales.

Hay que tener presente que el CGP desde su creación tuvo la intensión de ser la columna procesal aplicable a todas las especialidades existentes en el derecho colombiano; no obstante, sería incoherente desconocer que dependiendo de cada rama se requieren o no de algunos procedimientos especiales, ello atendiendo a el tipo de derechos que se debaten en juicio, y la multiplicidad de problemas jurídicos que se deben resolver en la sociedad. Por esto, de cierta manera, el CGP encuentra frustrado el deseo de convertirse en un código procesal único, general y omnipotente, sin desconocer su relevancia en su aplicación por remisión analógica.

El anterior predicado, se puede evidenciar flagrantemente, en lo que atiende a las medidas cautelares innominadas que precisa en su artículo 590, numeral 1 , literal c, y que aunque son indefectiblemente valiosas, en el ordenamiento procesal laboral, y que podrían ser viabilizadas en virtud de la remisión analógica, el decreto de estas cautelas innominadas no resulta del todo coherente, cuando de la lectura íntegra del artículo 590 del CGP, se evidencia que el demandante debe asumir el pago del veinte por ciento (20\%) del valor de las pretensiones, y aunque el legislador le dio la potestad al juez de incrementar o disminuir el monto de dicha caución, esta circunstancia pone en tensión dos principios: la gratuidad y el de tutela jurisdiccional efectiva.

\section{Conclusiones}

1. El derecho de acceder a la administración de justicia, tiene como principio activo, la tutela jurisdiccional efectiva, la cual permite la realización del derecho sustancial, su salvaguarda y ante todo su primacía frente al derecho adjetivo. Razón por la cual, las nuevas tendencias del derecho visualizan la creación de herramientas jurídicas que viabilicen estos presupuestos. Por ello, el Código General del Proceso (en adelante CGP) incorporó las medidas cautelares 
innominadas, estas pretenden ser la orientación para que todo el andamiaje procesal, sin distinguir la especialidad, las emplee con la debida adecuación. Así las cosas, en el orbe laboral, es indispensable su implementación, en pro de materializar los ideales de justicia y, en símil sentido, recobrar la confianza en el régimen jurídico.

2. Con la adopción de las Medidas Cautelares Innominadas, existe un cierto nivel de contingencia; bajo esta premisa, el juez debe adoptarlas desde una arista preventiva, toda vez que se enfrenta al desafío de evitar una esporádica inseguridad jurídica con ocasión al decreto de la cautela. En este orden, su determinación y consolidación debe estar respaldada de criterios íntegros y razonables que soporten el equilibrio de las garantías procesales.

3. Con el trascurrir del despliegue procesal, se ha venido impulsando las medidas cautelares innominadas, para contrarrestar la incertidumbre de un sistema basado en el paradigma de la legalidad, que ha convertido a un juez acucioso y justo, en un concurrente de decisiones infructuosas; los instrumentos cautelares innominados, devuelven al administrador de justicia de cierta manera, el componente actitudinal que conlleva a la materialización de la justicia y a la consolidación del Estado Social de Derecho.

4. En correspondencia con el Código Procesal del Trabajo y de la Seguridad Social, en su artículo 48, el juez es el gran director del proceso, y es él, quien debe adoptar las medidas necesarias y proporcionales para garantizar la prevalencia de las garantías ius-fundamentales, guardando el debido respeto por la imparcialidad en el trámite. En este orden de ideas, es pertinente hacer alusión al artículo 590, numeral 1, literal c del CGP, que pone de manifiesto la realización del derecho material, a través de cautelas atípicas o innominadas, las cuales aportan diligencia y eficacia a la administración de justicia; convirtiendo al juez en dinamizador del proceso, tras haberse realizado por la parte legitimada la petición de una medida que no se encuentra taxativa en el ordenamiento procesal.

5. Las medidas cautelares dentro de los diferentes escenarios procesales del ordenamiento jurídico Colombiano, ha venido cambiando su paradigma, pese a las modificaciones acontecidas posee un férreo enlace con la tutela jurisdiccional efectiva; sin embargo con la nueva figura jurídica adoptada por el CGP de cautelas innominadas, se debe mantener por parte del Director del proceso cierto margen de imparcialidad y de no arbitrariedad frente a las cautelas decretadas, en razón a su esencia de potestad discrecional, respetando los diversos márgenes que delimitan las actuaciones procesales.

6. Para concluir, el artículo 85 A del CPTSS, se torna deficiente e inseguro, dado que no salvaguarda la prevalencia del derecho sustancial, y tampoco garantiza el aseguramiento de la eventual sentencia en los procesos ordinarios (declarativos); aunado a ello, su redacción no es coherente con el alcance que se 
ufana de tener inserto, toda vez que el legislador se jactó de "garantizar las resultas del proceso" al mencionar el pago de una caución irrisoria a cargo del demandado, que estriba entre el 30\% y el 50\% del valor de las pretensiones del demandante, pero buena parte de las pretensiones quedan desprotegidas junto con la propia materialización de la sentencia; y, en segundo ítem, este postulado normativo se determina como escaso, por no disponer de un amplio catálogo de medidas cautelares.

7. Con fundamento en lo anterior, en asuntos laborales, es necesaria y esencial la inclusión de las cautelas innominadas precisadas en el CGP, que en un principio se pueden aplicar de manera análoga, encontrando su sustento en el artículo 145 del CPTSS, e indicarle al juez la necesidad de ponderar entre el principio de gratuidad y el de tutela jurisdiccional efectiva; pero, posteriormente, las cautelas genéricas o innominadas requieren un debido desarrollo legal que propenda por su adecuación estructural en la esfera laboral.

\section{Referencias bibliográficas}

BERIZONCE, Roberto Omar. Activismo judicial y participación en la construcción de las políticas públicas. En Revista Virtual Del Instituto Colombiano de Derecho Procesal No 36. 2010. Recuperado el 18 de junio de 2014; de [www.icdp.org.co/revista/ articulos/36/Roberto\%20Omar\%20Berizonce.pdf].

BONETT ORTÍZ, Samir Alberto. "Incidencia del Código General del Proceso en el proceso laboral. Medidas cautelares". En Memorias XXXV Congreso Colombiano de Derecho procesal. Bogotá: Universidad Libre e Instituto Colombiano de Derecho Procesal, 2014.

CALVINHO, Gustavo. La procedimentalización posmoderna. En: Revista del Instituto Colombiano de Derecho Procesal. Bogotá D.C: No 39, 2013.

CANOSA SUÁREZ, Ulises. Código General del Proceso. Propósitos. Bogotá: Secretaría General ICDP. 2012.

CARNELUTTI, Francesco. Cómo nace un proceso. [Santiago Sentís Melendo y Marino Ayerra Redín, Trad.]. Segunda edición. Bogotá: Editorial Temis S.A. Monografías Jurídicas No 56, 2002.

, Metodología del Derecho. [Santiago Sentís Melendo y Marino Ayerra Redín, Trad.]. Bogotá: Editorial Temis S.A. Monografías Jurídicas No 17. 2011.

CHEVALLIER, Jacques. El Estado posmoderno. [L'Etat post-moderne, tr Oswaldo Pérez]. Primera edición en castellano. Bogotá: Universidad Externado de Colombia. 2011.

COLOMBIA. Corte Constitucional. Sala Plena. Sentencia C-431/95. Bogotá, D.C., septiembre 28 de 1995. MP. Hernando Herrera Vergara. Expediente. D-870.

, Sentencia C-925/99. Bogotá, D.C., noviembre 18 de 1999. MP. Vladimiro Naranjo Mesa. Expediente D-2407.

, Sentencia C-523/ 09. Bogotá, DC., agosto 4 de 2009. MP. María Victoria Calle Correa. Expediente D-7612.

ISSN 2346-3473 • pp. 205-228 • Julio - Diciembre de 2017 • Bogotá, D.C. - Colombia 
Las cautelas innominadas en el proceso laboral colombiano

, Sentencia C-835/13. Bogotá, D.C., noviembre 20 de 2013. MP. Nilson Pinilla Pinilla. Expediente D-9626.

, Sentencia SU.447/11. Bogotá, D.C., mayo 26 de 2011. MP. Mauricio González Cuervo. Expedientes T-2.089.121 y T-2.180.640 (acumulados).

COLOMBIA. Corte Suprema de Justicia. Sala de Casación Civil. ST.C2343-2014. Bogotá, D. C., febrero 27 de 2014. MP. Luis Armando Tolosa Villabona. Radicación No. 11001-02-03-000-2014-00342-00.

CONGRESO DE LA REPÚBLICA DE COLOMBIA. Decreto-Ley 2158 de 1948. Mediante el cual se expide el Código Procesal del Trabajo y de la Seguridad Social.

, Ley 712 de 2001. Por la cual se reforma el Código Procesal del Trabajo. Diciembre 5 de 2001. DO. No. 44.640 de 8 de diciembre de 2001.

, Ley 1564 del 2012. Por medio de la cual se expide el Código General del Proceso y se dictan otras disposiciones: Julio 12. Diario Oficial No. 48.489 de 12 de julio de 2012.

FLÓREZ GACHARNÁ, Jorge. Los actos procesales de cautela en el proceso judicial dentro del estado social de derecho. En: Revista Virtual Del Instituto Colombiano de Derecho Procesal No 35 - 2009. Recuperado: el 18 de junio de 2014. De [http://www. icdp.org.co/revista/articulos/35/Jorge\%20Florez\%20Gacharna.pdf].

INSTITUTO COLOMBIANO DE DERECHO PROCESAL [ICDP]. Exposición de motivos del proyecto de Código General del Proceso. 2005. Recuperado en junio 28 de 2014, de [http://www.icdp.org.co/descargas/cgp/PresentacionCGP.pdf].

PARRA QUIJANO, Jairo. Medidas cautelares en el Código General del Proceso. En Forero Silva, Jorge (prólogo). Primera edición. Bogotá: Pontificia Universidad Javeriana: Editorial Temis. 2013.

, Medidas cautelares innominadas. En Memorias XXXIV Congreso Colombiano de Derecho Procesal. Bogotá: Universidad Libre de Colombia e instituto Colombiano de Derecho Procesal. 2013.

PODETTI, Ramiro. Tratado de las medidas cautelares. Segunda edición. Buenos Aires: Editorial EDIAR. 1955. Recuperado en junio 19 de 2014. De [http://venezuelaprocesal.net/Podettimedidas.pdf].

RENGEL ROMBERG, Aristides. Las medidas cautelares innominadas. En Revista Virtual del Instituto Colombiano de Derecho Procesal No 20.1996. Recuperado el 18 de junio de 2014, de [http://www.icdp.co/revista/articulos/8/MADIDAS\%20CAUTELARES\%20 INNOMINADAS-\%20ARISTIDES\%20RANGEL\%20ROMBERG.pdf].

RESTREPO MEDINA, Manuel Alberto. Perspectiva constitucional sobre la tutela cautelar judicial. El caso colombiano. Saberes- Revista de estudios jurídicos, económicos y sociales. Volumen 4. Madrid-España:Universidad Alfonso X el Sabio Avda. Villanueva de la Cañada. Separata 1: 26. 2006. Recuperado en junio 19 de 2014. De [http://www.uax. es/publicacion/perspectiva-constitucional-sobre-la-tutela-cautelar-judicial-el-caso-colombiano.pdf].

ROJAS GONZÁLEZ, Germán Eduardo. Esencia y trámite de la función cautelar. Primera Edición. Bogotá: Editorial Doctrina y Ley. 1996.

VON IHERING, Rudolph. La lucha por el derecho. Bogotá: Editorial Temis S.A. Monografías Jurídicas № 72. 2000. 